\title{
Subventricular zone neural progenitors reverse TNF-alpha effects in cortical neurons
}

\author{
Raffaella Morini ${ }^{1,2}$, Elsa Ghirardini ${ }^{1,2}$, Erica Butti ${ }^{3}$, Claudia Verderio ${ }^{2,4}$, Gianvito Martino ${ }^{3}$ and Michela Matteoli ${ }^{2,4^{*}}$
}

\begin{abstract}
Introduction: Tumor necrosis factor alpha (TNFa) plays a physiological role in controlling synaptic transmission and plasticity in the healthy central nervous system by modulating glutamate receptor trafficking to the plasma membrane. TNFa expression is also rapidly induced in response to tissue injury and infection. By promoting the insertion of $\mathrm{Ca}^{2+}$ permeable-AMPA receptors into the neuronal plasma membrane, this cytokine may cause excessive $\mathrm{Ca}^{2+}$ influx into neurons, thus enhancing neuronal death.
\end{abstract}

Methods: Primary cultures of cortical neurons were obtained from E18 foetal mice and incubated for $24 \mathrm{~h}$ with adult neural stem cells (aNPCs) either stimulated with lipopolysaccharide (LPS $\left.{ }^{+} \mathrm{NNPCs}\right)$ or not (aNPCs). Cultures were treated with TNFa $(100 \mathrm{ng} / \mathrm{ml})$, and electrophysiological recordings were performed in different conditions to evaluate the effect of the cytokine on neuronal transmission.

Results: In this study, we demonstrate that aNPCs from the subventricular zone reverse the effects induced by the cytokine. Moreover, we show that the effect of aNPCs on cortical neurons is mediated by cannabinoid CB1 receptor activation.

Conclusion: These data suggest that the role of aNPCs in preventing excitatory neurotransmission potentiation induced by TNFa on cortical neurons may have important implications for pathologies characterized by an inflammatory component affecting cortical neurons such as Alzheimer's disease.

\section{Introduction}

The pro-inflammatory cytokine tumor necrosis factor alpha (TNF $\alpha$ ), released by glial cells, is involved in several brain functions. Under physiological conditions, the cytokine is thought to be responsible for the activitydependent homeostatic regulation of synaptic connectivity, which consists of the increase of synaptic strength in response to prolonged blockade of activity. This process, termed synaptic scaling, involves the insertion of AMPA receptors, mobilized from intracellular stores, into the plasma membrane [1-4].

However, because an excess of cell surface localized AMPA receptors might predispose the neuron to glutamate-mediated excitotoxicity and excessive intracellular calcium concentrations, an increase in the amount of TNF $\alpha$ released by microglia as a consequence of immune

\footnotetext{
* Correspondence: michela.matteoli@humanitasresearch.it

${ }^{2}$ Humanitas Clinical and Research Center, via Manzoni 56, 20089 Rozzano, Italy

${ }^{4}$ National Research Council, Institute of Neuroscience, via Vanvitelli 32, 20129 Milan, Italy

Full list of author information is available at the end of the article
}

activation may lead to neuronal death $[5,6]$. In recent years, TNF $\alpha$ actions have been implicated consistently and increasingly in central nervous system (CNS) pathology. In particular, elevated TNF $\alpha$ levels have been reported in multiple sclerosis, stroke, ischemia, and epilepsy [7-12]. A crucial role of TNF $\alpha$ has also been reported in Alzheimer's disease (AD) [13]. More specifically, TNF $\alpha$ is upregulated in patients with $\mathrm{AD}$ [14], and polymorphisms of the TNF $\alpha$ gene affect the risk of developing AD [15].

Recent evidence has indicated that microglial TNF $\alpha$ production plays a critical role in the induction of neuronal cell cycle events in $\mathrm{AD}$, which are toxic for terminally differentiated neurons and lead to neurodegeneration [16]. Consistent with a role of TNF $\alpha$ in AD, perispinal administration of etanercept, a potent anti-TNF fusion protein, produced sustained clinical improvement in a 6-month, open-label pilot study in patients with mild to severe $\mathrm{AD}$ (reviewed in [17]).

It has recently been found that adult neural stem/precursor cells (aNPCs) located within the subventricular zone (SVZ) adapt their functions to the needs of the 
tissue, carrying out a broad spectrum of "bystander" nonneurogenic roles aimed at the maintenance of brain homeostasis, besides purely neurogenic functions [18]. In chronic inflammatory conditions, NPCs seem to be driven toward cell replacement, differentiating into new cellular elements in order to replace lost endogenous cells. Conversely, in acute inflammatory conditions, NPCs tend to remain undifferentiated and promote CNS tissue healing via the secretion of immunomodulatory and neuroprotective molecules that are capable of reducing detrimental tissue responses (reviewed in [19]). A continuous crosstalk between immune cells and NPCs appears to determine both the efficacy of endogenous regenerative responses and mechanism of action as well as the fate and functional integration of grafted NPCs, through different kinds of receptors located on their membranes [20,21].

The non-neurogenic function has been demonstrated in stroke, where newly formed NPCs that were not integrated into the neural network were shown to provide protection from tissue injury via the secretion of neurotrophic factors [22, 23]. Additionally, NPCs have been recently found to play an "innate" homeostatic regulatory role, likely aimed at the prevention of reactive inflammation, by protecting striatal neurons from glutamatemediated excitotoxicity [24]. More specifically, SVZderived aNPCs reverted the increased frequency and duration of spontaneous excitatory post-synaptic currents induced by exposure of striatal neurons to TNF $\alpha$ [24]. Whether the protective effect of aNPCs on striatal neurons extends to different neuronal populations subjected to pathological insults remains unknown. Given the established pathological role of TNF $\alpha$ in different diseases, we aimed at investigating whether SVZ-derived aNPCs are able to revert the effects of this cytokine also in cortical neurons, which represent the main target cells for neurodegenerative processes such as those occurring in Alzheimer's disease.

\section{Methods}

\section{Ethics statement}

All the experimental procedures followed the guidelines established by the Italian Council on Animal Care and were approved by Italian Government decree 27/2010.

\section{Cell cultures and drug treatments}

Primary neuronal cultures from cerebral cortex were obtained from E18 C57Bl/6 mice as described by Bartlett and Banker (1984) [25] with slight modifications as in [26]. Briefly, cortices were removed and dissociated by treatment with trypsin $\left(0.125 \%\right.$ for $15 \mathrm{~min}$ at $\left.37{ }^{\circ} \mathrm{C}\right)$ followed by trituration with a polished Pasteur pipette. The dissociated cells were plated onto glass coverslips coated with poly- $L$-lysine at a density of 400 cells $/ \mathrm{mm}^{2}$. The cells were maintained in Neurobasal medium
(Waltham, MA USA 02451) with B27 supplement, penicillin-streptomycin (10,000 units $/ \mathrm{ml}), 2 \mathrm{mM}$ glutamine, and $12.5 \mu \mathrm{M}$ glutamate (neuronal medium).

TNF $\alpha(100 \mathrm{ng} / \mathrm{ml})$ was incubated with neurons for $30 \mathrm{~min}$ prior to electrophysiological recordings and was present during the recordings [2], in the presence or absence of the neutralizing mouse TNF- $\alpha$ antibody $(0.5 \mu \mathrm{g} /$ $\mathrm{ml}$; R\&D Systems, Minneapolis, MN, USA) to neutralize the biological activity of mouse TNF- $\alpha$. The cannabinoid antagonist AM251 was added to the cortical neurons at a final concentration of $5 \mu \mathrm{M}$ for $2 \mathrm{~h}$ and was present during recordings [27].

\section{Generation and maintenance of aNPC cultures}

aNPC cultures were obtained from 6-week-old C57Bl/6 mice, as previously described [28]. Briefly, 3-mm-thick coronal sections were obtained from the anterior forebrain of 6-week-old mice ( $2 \mathrm{~mm}$ from the anterior pole of the brain). Dorsal SVZs were carefully dissected by using fine scissors in the following dissociating medium: Earl's Balanced Salt Solution (Gibco, Invitrogen) supplemented with $1 \mathrm{mg} / \mathrm{ml}$ Papain $27 \mathrm{U} / \mathrm{mg}$ (Sigma-Aldrich, St. Louis, MO, USA), $0.2 \mathrm{mg} / \mathrm{ml}$ Cysteine (Sigma-Aldrich), and $0.2 \mathrm{mg} / \mathrm{ml}$ EDTA (Sigma-Aldrich). Then, dissected tissue was incubated in the same solution for $30 \mathrm{~min}$ at $37^{\circ} \mathrm{C}$ on a rocking platform. Finally, dissociated cells were plated in standard neurosphere growth medium Neurocult proliferation medium (Stemcell Technology, Vancouver, BC, Canada) supplemented with epidermal growth factor (EGF) $(20 \mathrm{ng} / \mathrm{ml})$ and fibroblast growth factor 2 (FGF2) $(10 \mathrm{ng} / \mathrm{ml})$. For each in vitro passage, single cells were obtained by incubating neurospheres in Accumax (SigmaAldrich) for $10 \mathrm{~min}$, and then $8000 \mathrm{cells} / \mathrm{mm}^{2}$ were plated on T75 plastic flasks (Nunc, Rochester, NY, USA). Neurospheres were propagated in vitro and assayed for self-renewal and cell differentiation after six passages, as previously described [28].

To label aNPCs, cells were transduced with a lentivirus [29] expressing green fluorescent protein (GFP); about $1.5 \times 10^{6}$ cells in $10 \mathrm{ml}$ were infected with $3 \times 10^{6}$ $\mathrm{tu} / \mathrm{ml}$ of GFP-lentivirus. The day after the transduction, the medium was replaced with a fresh one and cells were allowed to grow. For LPS stimulation, aNPCs were dissociated, incubated with $100 \mathrm{ng} / \mathrm{ml}$ of LPS (026:B6; Sigma-Aldrich), and then collected after $16 \mathrm{~h}$.

\section{Cell culture electrophysiology}

Whole-cell voltage-clamp recordings were performed on mouse primary cortical neurons at 13-15 days in vitro. During recordings, cells were bathed in a standard external solution containing (in $\mathrm{mM}$ ): $125 \mathrm{NaCl}, 5 \mathrm{KCl}, 1.2$ $\mathrm{MgSO}_{4}, 1.2 \mathrm{KH}_{2} \mathrm{PO}_{4}, 2 \mathrm{CaCl}_{2}, 6$ glucose, and 25 HEPES$\mathrm{NaOH}, \mathrm{pH}$ 7.4. Recording pipettes were fabricated from borosilicate glass capillary by using a horizontal puller 
(Sutter Instrument Company, Novato, CA, USA) inducing tip resistances of 3-5 $\mathrm{M} \Omega$ and filled with a standard intracellular solution containing (in $\mathrm{mM}$ ): $130 \mathrm{~K}$-gluconate, $10 \mathrm{KCl}, 1 \mathrm{EGTA}, 10$ HEPES- $\mathrm{NaOH}, 2 \mathrm{MgCl}_{2}, 4$ MgATP, and 0.3 Tris-GTP. For miniature excitatory postsynaptic current (mEPSC) recordings, $1 \mu \mathrm{M}$ tetrodotoxin, $20 \mu \mathrm{M}$ Bicuculline, and $50 \mu \mathrm{M}$ AP5 (Tocris Bioscience, Bristol, UK) were added to standard extracellular solution to block spontaneous action potential propagation, GABA-A, and NMDA receptors, respectively. Recordings were performed at room temperature in voltage clamp mode at a holding potential of $-70 \mathrm{mV}$ by using a Multiclamp 700B amplifier (Molecular Devices, Sunnyvale, CA, USA) and pClamp-10 software (Axon Instruments, Foster City, CA, USA). Series resistance ranged from 10 to 20 $\mathrm{M} \Omega$ and was monitored for consistency during recordings. Cells in culture with leak currents of more than 100 pA were excluded from the analysis. Signals were amplified, sampled at $10 \mathrm{kHz}$, filtered to 2 or $3 \mathrm{KHz}$, and analyzed by using pClamp 10 data acquisition and analysis program. To verify the specific effect of adult NPCs, cultured cortical neurons were incubated for 24 h prior to electrophysiological recordings with either lipopolysaccharide-stimulated ( $\mathrm{LPS}^{+} \mathrm{aNPCs}$ ) or unstimulated aNPCs. Only cortical neurons surrounded by aNPCs were selected to record.

\section{Immunofluorescence staining of dissociated neurons}

Neuronal cultures were fixed with $4 \%$ paraformaldehyde and $4 \%$ sucrose. The following antibodies were used: rabbit anti-CB1 (1:500; Synaptic System, Goettingen, Germany), guinea pig anti-vGLUT1 (1:1000; Synaptic System), and guinea pig anti -VGAT (1:750; Synaptic System). Secondary antibodies were conjugated with Alexa-488 and Alexa-555 fluorophores (Invitrogen).

Images were acquired by using a Leica Spe confocal microscope equipped with an ACS APO 63.0X1.3 objective (Leica, Wetzlar, Germany).

Pixel size was $94.8 \mathrm{~nm} \_94.8 \mathrm{~nm}$, and acquisition parameters (i.e., laser power, gain, and offset) were kept constant across different experimental settings. The minimum puncta size was set at three pixels.

Colocalization of two selected markers was measured by using the boolean function "and" for the selected channels. The resulting image was binarized, inverted, and used as a colocalization mask to be subtracted from single channel. The number of puncta resulting from colocalization mask subtraction (colocalizing puncta) was measured for each marker. A colocalization ratio was set as colocalized area/total puncta aerea. Fluorescence image processing and analyses were performed with the ImageJ Software (National Institutes of Health, Bethesda, MD, USA).
Hoechst 33342/PI double-stain cell death detection essay To distinguish between living and dead cell populations and assess the percentage of neuronal death after AM251, cultured neurons were incubated for $15 \mathrm{~min}$ at $37^{\circ} \mathrm{C}$ with Hoechst 33342 (final concentration, $1 \mathrm{ug} / \mathrm{ml}$; SigmaAldrich) and propidium iodide (PI) (final concentration, $1 \mu \mathrm{g} / \mathrm{ml}$; Sigma-Aldrich) dissolved in neuronal medium. PI is a red-fluorescence dye (excitation/emission maxima $\sim 535 / 617 \mathrm{~nm}$, when bound to DNA) which is only permeant to dead cells, whereas the blue-fluorescent Hoechst 33342 dye (excitation/emission maxima $\sim 350 / 461 \mathrm{~nm}$, when bound to DNA) is specifically used to stain the nuclei of living or fixed cells and tissues. Fluorescence images resulting from the simultaneous use of these dyes, acquired by using an inverted Olympus IXB53 microscope (Olympus, Tokyo, Japan), allowed us to determine the number of dead neurons in our experimental conditions.

\section{Statistical analysis}

Patch clamp experiments were analyzed by using pClamp 10 data acquisition and analysis program and fluorescence image processing and analyses were performed with the ImageJ Software. Statistical analysis was performed by using PRISM 6 software (GraphPad Software Inc., San Diego, CA, USA). After testing whether data were normally distributed or not, the appropriate statistical test has been used (see figure legends). $\mathrm{n}$ refers to the number of elements analysed. Data are presented as mean \pm standard error of the mean from the indicated number of elements analysed. The differences were considered to be significant if $P$ value of less was than 0.05 and are indicated by an asterisk; those at $P$ value of less than 0.01 are indicated by double asterisks.

\section{Results}

TNFa increases amplitude and frequency of miniature currents in primary cortical neurons

Although several studies have shown that TNF $\alpha$ increases synaptic strength at hippocampal excitatory synapses by rapidly inserting AMPA receptors via TNFR1 receptor activation [30], little has been reported in different neuronal cell types [31,32]. To address whether this effect is restricted to hippocampal neurons or also occurs at cortical synapses, we grew cultures of primary neurons derived from the cerebral cortex and exposed them to TNF $\alpha$ $(100 \mathrm{ng} / \mathrm{ml})$ for $30 \mathrm{~min}$ before recording mEPSCs. Our data showed a significant increase in both frequency and amplitude of mEPSCs in TNF $\alpha$-treated neurons with respect to untreated control neurons (Fig. 1). This effect was completely blocked in the presence of neutralizing TNF $\alpha$ antibodies. These data indicate that cortical neurons respond to TNF $\alpha$ in a manner that is similar to hippocampal neurons and indicate that this cytokine may predispose cortical neurons to excitotoxic phenomena. 
A

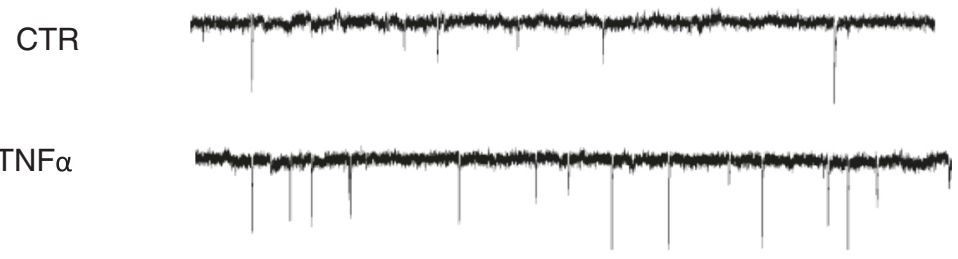

$\mathrm{TNF} \alpha+$

Neutralizing Abs

B

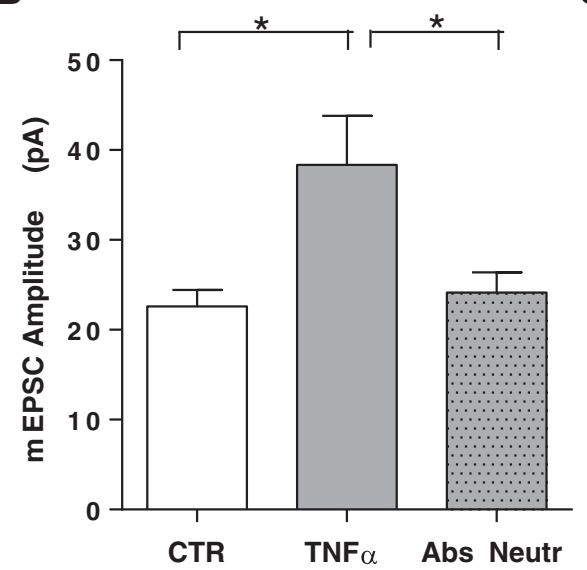

C

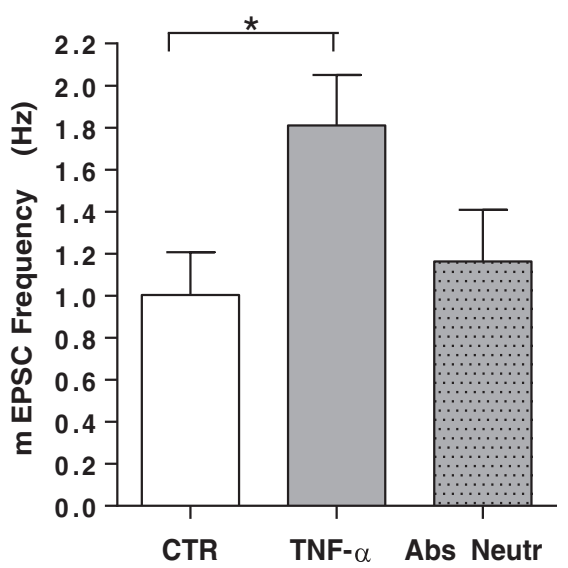

Fig. 1 TNFa increases mEPSC frequency and amplitude in cortical neurons. a Examples of voltage-clamp recordings of mEPSCs from cultured cortical neurons in control conditions, upon treatment with TNFa $(100 \mathrm{ng} / \mathrm{ml} 30 \mathrm{~min})$ or in the presence of TNFa and neutralizing Abs (0.5 $\mu \mathrm{g} / \mathrm{ml}$; R\&D Systems) (calibration bars: 20 pA, 200 ms). b, c Group data of average mEPSC amplitude and frequency in untreated $(n=15)$, TNFa-treated $(n=13)$, and TNFa plus neutralizing Ab-treated $(n=10)$ cells. A significant increase in average mEPSC amplitude and frequency is produced by TNFa, completely blocked by neutralizing anti -TNFa Abs $(P<0.05)$. All data are expressed as mean \pm standard error of the mean. Statistical test: one-way analysis of variance, Dunn's multiple comparisons test. Ab antibody, mEPSC miniature excitatory post-synaptic current, TNFa tumor necrosis factor alpha

\section{Adult NPCs revert the effect of TNFa treatment in cortical neurons}

Both injury and neurodegenerative diseases increase the amount of TNF $\alpha$ in the brain and this contributes to neuronal death. Recent studies demonstrated that SVZ-derived aNPCs protect striatal neurons from glutamate-mediated toxicity in pathological conditions associated with inflammation and excitotoxicity, such as epilepsy and ischemic stroke [24]. To assess whether the neuroprotective effects of aNPCs extend to different neuronal types, we exposed neurons to TNF $\alpha$ before or after incubating them for $24 \mathrm{~h}$ with $\mathrm{LPS}^{+}$aNPCs in order to mimic the effects of different danger (or recognition) signals triggering the inflammatory response. aNPCs were infected in order to express GFP [29], and only neurons surrounded by aNPCs were selected to record (Fig. 2a). Notably, membranous structures of small and medium size, including round membrane vesicles, were detected on the cell surface of aNPCs (Fig. 2b left panel), as recently described [33]. These vesicles were released by aNPCs (Fig. $2 \mathrm{~b}$ middle panel) and adhered to GFP-negative neuronal cells (Fig. 2b right panel).

Voltage clamp recordings of cortical neurons surrounded by aNPCs revealed that the increase in average mEPSC frequency due to TNF $\alpha$ was fully prevented by treatment of the cultures with $\mathrm{LPS}^{+}$aNPCs (Fig. 2). A clear tendency for recovery of mEPSC amplitude was also observed, although statistical significance was not reached. No difference in mEPSC frequency and amplitude was detected when $\mathrm{LPS}^{+}$aNPCs were added to cell cultures in the absence of TNF $\alpha$ (Fig. 2). Furthermore, compared with striatal neurons where aNPCs exert a regulatory role only when previously exposed to LPS [24], both LPS-treated and LPS-untreated NPCs appeared effective in preventing the changes in mEPSC frequency and amplitude in cortical neurons following TNF $\alpha$ administration. However, in the case of LPSuntreated aNPCs, a statistically significant recovery was 


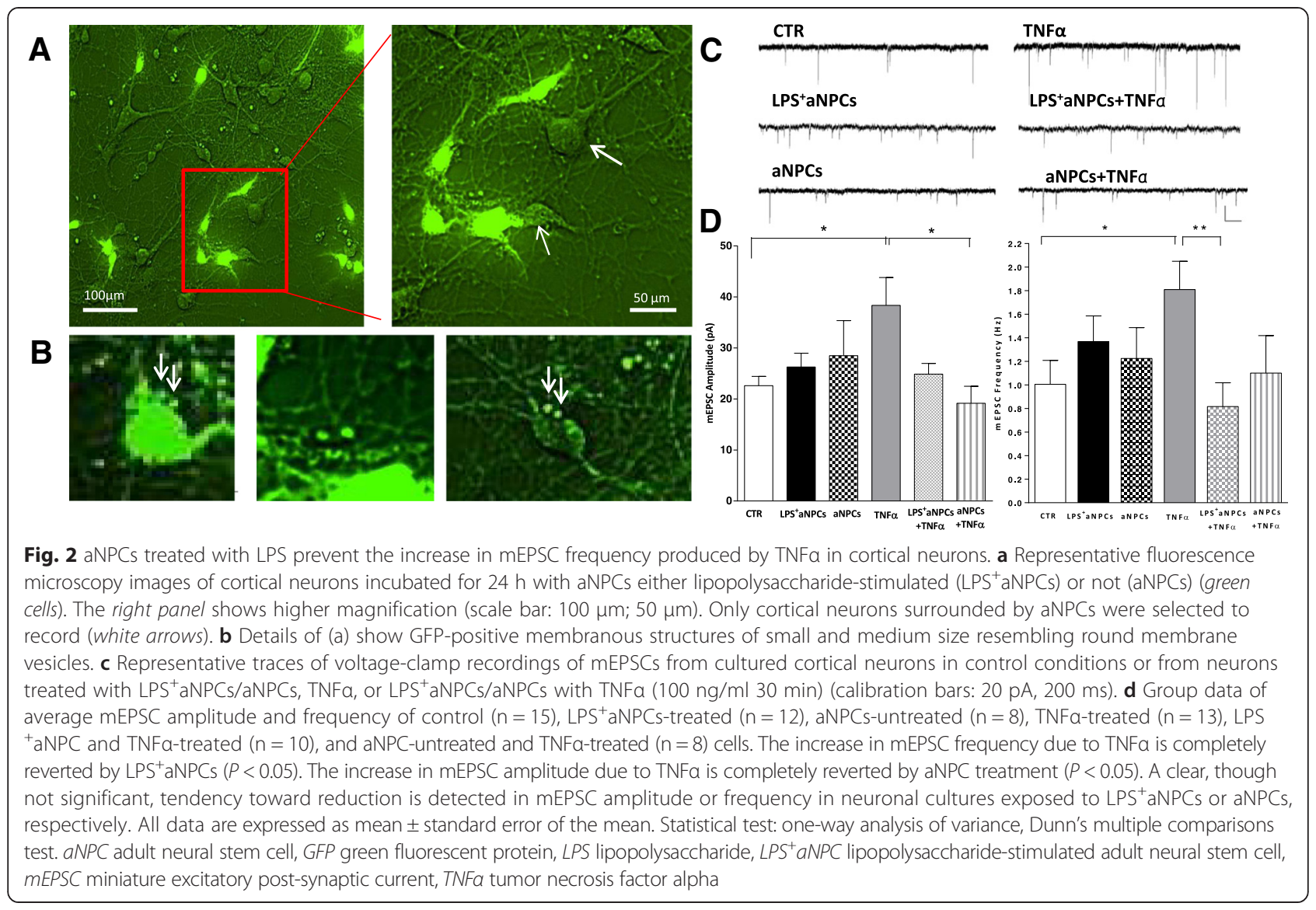

evident only in mEPSC amplitude (Fig. 2). These data indicate that aNPCs can revert the TNF $\alpha$-induced mEPSC alterations.

\section{Adult neural stem/progenitor cells act via $\mathrm{CB} 1$ receptor activation}

The protective role of type 1 cannabinoid receptors (CB1), against enhanced excitotoxic death caused by TNF $\alpha$ and other harmful agents, has been demonstrated by several studies [34, 35]. Furthermore, it has been found that aNPCs are capable of secreting endogenous cannabinoids $[24,36]$. We therefore aimed to test whether, in our experimental conditions, aNPCs exert their described effect through CB1 receptor activation. To this end, we recorded mEPSCs in TNFo-treated cortical neurons incubated with aNPCs in the presence of the CB1 antagonist AM251 (Fig. 3). The results showed that $\mathrm{LPS}^{+}$aNPC treatment fails to revert TNF $\alpha$ effects in the presence of AM251, indicating that aNPCs act through CB1 receptor activation. As already shown in previous reports [37-39], CB1 receptors were expressed mainly in inhibitory neurons (Fig. 3d) and their localization did not change when neurons were exposed to AM251 (Fig. 3e). Our results demonstrate that CB1 is present in both inhibitory and excitatory synapses but that the signal overlap is approximately 10 times higher in inhibitory synapses than in excitatory ones (Fig. 3e). Additional file 1: Figure S1 shows that AM251 per se did not significantly change mEPSC frequency and amplitude (A), did not display cytotoxic effects (B), and did not change the synaptic expression of CB1 receptors $(C, D)$.

\section{Discussion}

TNF $\alpha$ plays a physiological role in controlling synaptic transmission and plasticity in the healthy CNS by modulating glutamate receptor trafficking to the plasma membrane $[2,3]$. Excitatory synapse scaling, caused by blockade of neuronal activity, is known to be mediated by TNF $\alpha$ which increases the insertion of AMPA receptors (of both GluR1 and GluR2 subunits) into the plasma membrane and decreases GABA-A receptor cell surface expression. Through this process, TNF $\alpha$ increases the mean frequency and amplitude of mEPSCs [31, 40, 41]. Consistently, in hippocampal cultures from TNF $\alpha$ deficient mice, no increase in mEPSC amplitude resulted from activity blockade, thus confirming the TNF $\alpha$ dependence of this increase [4]. In the present study, we confirm the effects of TNF $\alpha$ in mEPSCs recorded from primary cultures of cortical neurons. 


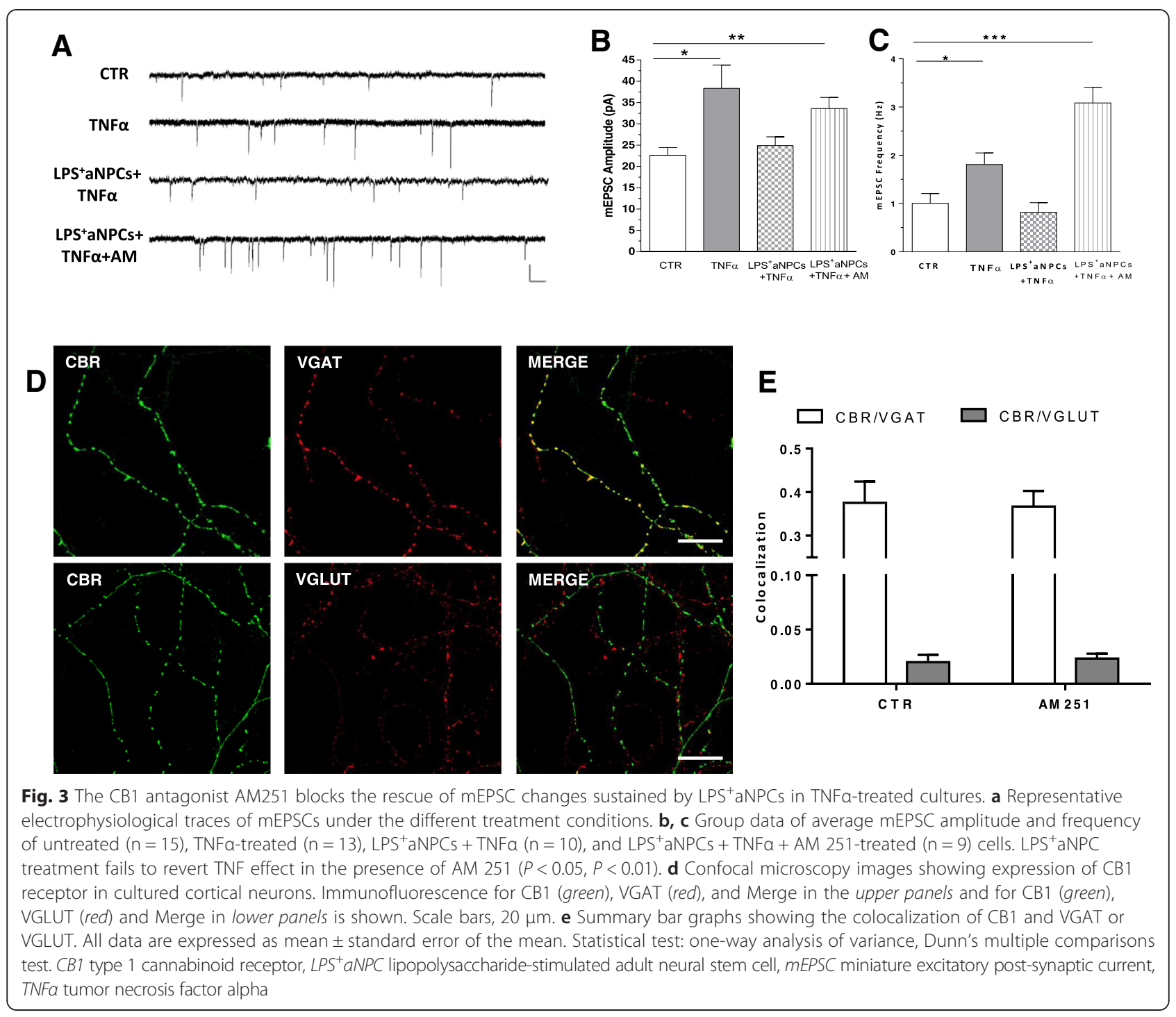

TNF $\alpha$ is rapidly induced in the CNS in response to tissue injury and infection [42, 43]. Although astrocytes and neurons are able to produce TNF $\alpha$, microglial cells are believed to be the major source of this cytokine during neuroinflammation [44]. Through TNFR1 signaling, TNF $\alpha$ promotes further cytokine release from microglia, as well as increasing glutamate exocytosis and inhibiting glutamate uptake from astrocytes, thus elevating extracellular glutamate levels. Under such conditions, the TNF $\alpha-$ mediated insertion of $\mathrm{Ca}^{+}$permeable-AMPA receptors into the neuronal plasma membrane may cause excessive $\mathrm{Ca}^{+}$influx into neurons and induce neuronal death. The dying neurons maintain microglia in an active state, releasing TNF $\alpha$. Through this loop, TNF $\alpha$ provides a link between neuroinflammatory and excitotoxic processes (reviewed in [45]).

It has recently been shown that SVZ-derived aNPCs play a role in protecting striatal medium spiny neurons from glutamatergic excitotoxicity, by reverting the increased frequency and duration of spontaneous excitatory post-synaptic currents induced by toxic or ischemic stressful stimuli or both [24]. In the present study, we demonstrate that aNPCs revert the effect of TNF $\alpha$ treatment also in cortical neurons, fully preventing the increase in mEPSC frequency. The increase in mEPSC amplitude, a typical consequence of TNF $\alpha$ treatment [2], was not observed in striatal neurons [24] where, besides frequency, only half width and decay time of mEPSCs were affected. Also, compared with previous work on striatal tissue slices [24], where the addition of LPSexposed aNPCs, but not of untreated aNPCs, reverted the EPSC changes produced by TNF $\alpha$, both untreated and LPS-treated aNPCs were effective in reverting either the frequency or the amplitude of TNF $\alpha$ effects in cortical neurons. These data indicate the existence of subtle, but potentially significant, differences among different 
brain areas in terms of both cytokine responsivity and the potential protective effects of aNPCs.

Although we cannot exclude that factors other than endocannabinoids may contribute to the observed phenomenon, we show that aNPC effects on cortical neurons are mediated by the activation of $\mathrm{CB} 1$ receptors, as demonstrated by the blockade on aNSC-mediated recovery of TNF $\alpha$ effects by the CB1 antagonist AM251. It is likely that the activation of CB1 receptors is a consequence of the secretion of endocannabinod arachidonoyl ethanolamide (AEA), a molecule that regulates glutamatergic tone through CB1 binding [24], by aNPCs. Endocannabinoids are likely to be released from aNPCs through extracellular membrane vesicles, which have been recently found to allow the movement of lipophilic endocannabinoids into the extracellular space to reach target neurons [38]. Notably, in line with Cossetti and colleagues [33], we have detected the formation of extracellular vesicles from the cell surface of aNPCs. These vesicles adhere to the membrane of cortical neurons, thus supporting the concept that they may actively mediate the communication of neural stem/precursor cells with the microenvironment. It ensues from this that stem cell therapies may work not only via cell replacement but also through a consistent intercellular molecule exchange [33].

The preventive effect of aNPCs on the potentiation of excitatory neurotransmission induced by TNF $\alpha$ in cortical neurons may have important implications. Indeed, across different pathological conditions, TNF $\alpha$ is thought to contribute to neuroinflammation in $\mathrm{AD}$. $\mathrm{A} \beta_{1-40}$ induces an increase in TNF $\alpha$ expression and oxidative alterations in the prefrontal cortex and hippocampus [46]. In support of the role of TNF $\alpha$ as a central mediator of $A \beta$ action, excess cytokine, at a level 25 times higher than controls, has been reported in the cerebrospinal fluid of patients with $\mathrm{AD}$, which correlates with progression from mild cognitive impairment to AD [47]. Quite notably, a percentage of neurons localized near the plaques of amyloid $\beta$ deposits display unexpected hyperactivity $[48,49]$, which might represent an early sign of neuronal excitotoxicity associated with impending synaptic failure and incipient cognitive decline $[50,51]$. In this respect, the possible protective role of aNPCs in mouse models of AD, where TNF $\alpha$ is increased and neurons display hyperactivity, deserves future investigation.

\section{Conclusions}

We demonstrated that aNPCs revert the TNF $\alpha$-induced increase in frequency and amplitude of mEPSCs in cortical neurons through the activation of $\mathrm{CB} 1$ receptors. By preventing the potentiation of excitatory neurotransmission in cortical neurons, which represents the main target for neurodegeneration in AD and other neurodegenerative pathologies, aNPCs may have significant translational potential.

\section{Additional file}

Additional file 1: Figure S1. AM251 treatment has no effect on synaptic activity, cell viability and CB1 receptor expression. A Representative electrophysiological traces and group data of average mEPSC amplitude and frequency of control $(n=10)$ and AM 251 treated $(n=9)$ cells (scale bar: 20 pA, 200 ms). B Fluorescence images of Hoechst and propidium iodide double staining in cortical neurons and summary bar graph showing lack of cytotoxic effects after AM251 treatment (scale bar: $40 \mu \mathrm{m}$ ). C, D Confocal microscopy images and summary bar graph showing expression of CB1 receptors in control and AM251 treated cultured neurons (scale bar: $20 \mu \mathrm{m}$ ). All data are expressed as mean \pm standard error of the mean. CB1 type 1 cannabinoid receptor, MEPSC miniature excitatory post-synaptic current. (PPT $1143 \mathrm{~kb}$ )

\section{Abbreviations}

AD: Alzheimer's disease; aNPC: Adult neural stem cell; CB1: Type 1 cannabinoid receptor; CNS: Central nervous system; GFP: Green fluorescent protein; LPS: Lipopolysaccharide; LPS ${ }^{+}$aNPC: Lipopolysaccharide-stimulated adult neural stem cell; mEPSC: Miniature excitatory post-synaptic current; NPC: Neural stem/precursor cell; PI: Propidium iodide; SVZ: Subventricular zone; TNFa: Tumor necrosis factor alpha.

\section{Competing interests}

The authors declare that they have no competing interests.

\section{Authors' contributions}

RM designed and performed most of the experiments, analysed the data and wrote the manuscript. EG helped to perform the experiments and analyse the data. MM conceived and designed the experiments and wrote the manuscript. All authors made contributions to the design and interpretation of data; have been involved in drafting the manuscript; and read and approved final manuscript.

\section{Acknowledgements}

This study has been supported by PRIN 2010-2011 2010JFYFY2_008, TELETHON GGP12115, Fondazione Italiana Sclerosi Multipla (FISM-R/17), CNR Research Project on Aging, Regione Lombardia Project MbMM-convenzione 18099/RCC to MM, argetBrain (EU Framework 7 project HEALTH-F2-2012-279017), and ITN Neurokine to GVM. RM and EB are supported by Fondazione Veronesi. We thank Costanza Capuano for critical reading of the manuscript.

\section{Author details}

'Department of Medical Biotechnology and Traslational Medicine, University of Milano, via Vanvitelli 32, 20129 Milan, Italy. ${ }^{2}$ Humanitas Clinical and Research Center, via Manzoni 56, 20089 Rozzano, Italy. Institute of Experimental Neurology, Division of Neuroscience, San Raffaele Scientific Institute and University, Via Olgettina 58, 20132 Milan, Italy. ${ }^{4}$ National Research Council, Institute of Neuroscience, via Vanvitelli 32, 20129 Milan, Italy.

Received: 22 December 2014 Revised: 12 May 2015 Accepted: 14 August 2015 Published online: 07 September 2015

\section{References}

1. Malinow R, Malenka RC. AMPA receptor trafficking and synaptic plasticity. Annu Rev Neurosci. 2002;25:103-26.

2. Beattie EC, Stellwagen D, Morishita W, Bresnahan JC, Ha BK, Von Zastrow M, et al. Control of synaptic strength by glial TNF-alpha. Science. 2002:295:2282-5.

3. Stellwagen D, Beattie EC, Seo JY, Malenka RC. Differential regulation of AMPA receptor and GABA receptor trafficking by tumor necrosis factor-alpha. J Neurosci. 2005;25:3219-28.

4. Stellwagen D, Malenka RC. Synaptic scaling mediated by glial TNFalpha. Nature. 2006;440:1054-9. 
5. Bruce AJ, Boling W, Kindy MS, Peschon J, Kraemer P, Carpenter MK, et al. Altered neuronal and microglial responses to excitotoxic and ischemic brain injury in mice lacking TNF receptors. Nat Med. 1996;2:788-94.

6. Combs CK, Karlo JC, Landreth GE. Beta-Amyloid stimulation of microglia and monocytes results in TNFalpha-dependent expression of inducible nitric oxide synthase and neuronal apoptosis. J Neurosci. 2001:21:1179-88.

7. Tchelingerian JL, Quinonero J, Booss J, Jacque C. Localization of TNF-a and IL-1-a immunoreactivities in striatal neurons after surgical injury to the hippocampus. Neuron. 1993;10:213-24.

8. Akiyama H, Barger S, Barnum S, Bradt B, Bauer J, Cole GM, et al. Inflammation and Alzheimer's disease. Neurobiol Aging. 2000;21:383-421.

9. Gimsa U, Peter SV, Lehmann K, Bechmann I, Nitsch R. Axonal damage induced by invading $T$ cells in organotypic central nervous system tissue in vitro: involvement of microglial cells. Brain Pathgology. 2000;10:365-77.

10. Yin L, Othaki H, Nakamachi T, Dohi K, Iwai Y, Funahashi $H$, et al. Expression of Tumor necrosis factor alpha (TNFalpha) following transient cerebral ischemia. Acta Neurochir Suppl. 2003;86:93-6.

11. Ravizza T, Rizzi M, Perego C, Richichi C, Veliskova J, Moshè SL, et al. Inflammatory response and glia activation in developing rat hippocampus after status epilepticus. Epilepsia. 2005;46:113-7.

12. Santello M, Volterra A. TNFa in synaptic function: switching gears. Trends Neurosci. 2012;35:638-47.

13. Zhang J, Peng M, Jia J. Plasma Amyloid- $\beta$ oligomero and soluble tumor necrosis factor receptors as potential Biomarkers of AD. Curr Alzheimer Res. 2014;11:325-31.

14. Perry RT, Collins JS, Wiener H, Acton R, Go RC. The role of TNF and its receptors in Alzheimer's disease. Neurobiol Aging. 2001;22:873-83.

15. Di Bona D, Candore G, Franceschi C, Licastro F, Colonna-Romano G, Cammà C, et al. Systematic review by meta-analyses on the possible role of TNF-alpha polymorphisms in association with Alzheimer's disease. Brain Res Rev. 2009:61:60-8. doi:10.1016/j.brainresrev.2009.05.001

16. Bhaskar K, Maphis N, Xu G, Varvel NH, Kokiko-Cochran ON, Weick JP, et al. Microglial derived tumor necrosis factor-a drives Alzheimer's disease-related neuronal cell cycle events. Neurobiol Dis. 2014;62:273-85. doi:10.1016/ j.nbd.2013.10.007.

17. Tobinick E, Kim NM, Reyzin G, Rodriguez-Romanacce H, DePuy V. Selective TNF inhibition for chronic stroke and traumatic brain injury: an observational study involving 629 consecutive patients treated with perispinal etanercept. CNS Drugs. 2012;26:1051-70. doi:10.1007/s40263-012-0013-2.

18. Martino G, Pluchino S. The therapeutic potential of neural stem cells. Nat Rev Neurosci. 2006;7:395-406.

19. Butti E, Cusimano M, Bacigaluppi M, Martino G. Neurogenic and non-neurogenic functions of endogenous neural stem cells. Front Neurosci. 2014;8:92.

20. Kokaia Z, Martino G, Schwartz M, Lindvall O. Cross-talk between neural stem cells and immune cells: the key to better brain repair? Nat Neurosci. 2012:15:1078-87

21. Compagnucci C, Di Siena S, Bustamante MB, Di Giacomo D, Di Tommaso M, Maccarrone M, et al. Type-1 (CB1) cannabinoid receptor promotes neuronal differentiation and maturation of neural stem cells. PLoS One. 2013:8:e54271

22. Jin K, Wang X, Xie L, Mao XO, Greenberg DA. Transgenic ablation of doublecortin-expressing cells suppresses adult neurogenesis and worsens stroke outcome in mice. Proc Natl Acad Sci U S A. 2010;107:7993-8.

23. Sun C, Sun H, Wu S, Lee CC, Akamatsu Y, Wang RK, et al. Conditional ablation of neuroprogenitor cells in adult mice impedes recovery of poststroke cognitive function and reduces synaptic connectivity in the perforant pathway. J Neurosci. 2013;33:17314-25.

24. Butti E, Bacigaluppi M, Rossi S, Cambiaghi M, Bari M, Silla AC, et al. Subventricular zone neural progenitors protect striatal neurons from glutamatergic excitotoxicity. Brain. 2012;135:3320-35.

25. Barlett WP, Banker GA. An electron microscopic study of the development of axons and dendrites by hippocampal neurons in culture. I. Cells which develop without intercellular contacts. J Neurosci. 1984;4:1944-53.

26. Fattorini G, Antonucci F, Menna E, Matteoli M, Conti F. Co-expression of V-Glut1 and Vgat sustains glutamate and GABA co-release and is regualted by activity in cortical neurons. J Cell Sci 2015; 128(9):1669-73.

27. Pertwee RG, Howlett AC, Abood ME, Alexander SP, Di Marzo V, Elphick MR, et al. International Union of Basic and Clinical Pharmacology. LXXIX. Cannabinoid receptors and their ligands: beyond CB1 and CB2. Pharmacol Rev. 2010;62:588-631.
28. Pluchino S, Martino G. Neural stem cell-mediated immunomodulation: repairing the haemorragic brain. Brain. 2008;131:604-5.

29. Follenzi A, Ailles LE, Bakovic S, Geuna M, Naldini L. Gene transfer by lentiviral vectors is limited by nuclear translocation and rescued by HIV-1 pol sequences. Nat Genet. 2000;25:217-22.

30. He P, Liu Q, Wu J, Shen Y. Genetic deletion of TNF receptor suppresses excitatory synaptic transmission via reducing AMPA receptors synaptic localization in cortical neurons. FASEB J. 2012;26:334-45.

31. Leonoudakis D, Braithwaite SP, Beattie MS, Beattie EC. TNFa-induced AMPA-receptor trafficking in CNS neurons; relevance to excitotoxicity? Neuron Glia Biol. 2004;1:263-73.

32. Steinmetz CC, Turrigiano GG. TNFa signaling maintains the ability of cortical synapses to express synaptic scaling. J Neurosci. 2010;30:14685-90.

33. Cossetti C, Iraci N, Mercer TR, Leonardi T, Alpi E, Drago D, et al. Extracellular vesicles from neural stem cells transfer IFN- $\gamma$ via Ifngr1 to activate Stat1 signaling in target cells. Mol Cell. 2014;56:193-204.

34. Zhao P, Leonoudakis D, Abood ME, Beattie E. Cannabinoids receptor activation reduces TNFa-induced surface localization of AMPAR-Type Glutamate receptors and excitotoxicity. Neuropharmacology. 2010;5882:551-8.

35. Zogopoulos P, Vasileiou I, Patsouris E, Theocharis S. The neuroprotective role of endocannabinoids against chemical-induced injury and other adverse effects. J Appl Toxicol. 2013;33:246-64.

36. Aguado T, Monory K, Palazuelos J, Stella N, Cravatt B, Lutz B, et al. The endocannabinoid system drives neural progenitor proliferation. FASEB J. 2005;19:1704-6.

37. Eggan SM, Lewis DA. Immunocytochemical distribution of the cannabinoid CB1 receptor in the primate neocortex: a regional and laminar analysis. Cereb Cortex. 2007:17:175-91.

38. Gabrielli M, Battista N, Riganti L, Prada I, Antonucci F, Cantone L, et al. Active endocannabinoids are secreted on extracellular membrane vesicles. EMBO Rep. 2015;16:213-20.

39. Kawamura Y, Fukaya M, Maejima T, Yoshida T, Miura E, Watanabe M, et al. The CB1 cannabinoid receptor is the major cannabinoid receptor at excitatory presynaptic sites in the hippocampus and cerebellum. J Neurosci. 2006;26:2991-3001

40. Ogoshi F, Yin HZ, Kuppumbatti Y, Song B, Amindari S, Weiss JH. Tumor necrosis- factor -alpha (TNF-alpha) induces rapid insertion of Ca2 + -permeable alpha-amino-3-hydroxyl-5-methyl-4-isoxazole-propionate (AMPA)/kainate (Ca-A/K) channels in a subset of hippocampal pyramidal neurons. Exp Neurol. 2005;193:384-93.

41. Leonoudakis D, Zhao P, Beattie EC. Rapid tumor necrosis factor alpha-induced exocytosis of glutamate receptor 2-lacking AMPA receptors to extrasynaptic plasma membrane potentiates excitotoxicity. J Neurosci. 2008:28:2119-30

42. Perry VH, Bell MD, Brown HC, Matyszak MK. Inflammation in the nervous system. Curr Opin Neurobiol. 1995;5:636-41.

43. Allan SM, Rothwell NJ. Cytokines and acute neurodegeneration. Nat Rev Neurosci. 2001;2:734-44

44. Smith JA, Das A, Ray SK, Banik NL. Role of pro-inflammatory cytokines released from microglia in neurodegenerative diseases. Brain Res Bull. 2012:87:10-20

45. Olmos $\mathrm{G}$, Llado J. Tumor necrosis factor alpha: a link between Neuroinflammation and excitotoxicity. Mediators Inflamm. 2014;2014:861231.

46. Medeiros R, Prediger RD, Passos GF, Pandolfo P, Duarte FS, Franco JL, et al. Connecting TNF-a signaling pathways to iNOS expression in a mouse model of Alzheimer's disease: relevance for the behavioral and synaptic deficits induced by amyloid $\beta$ protein. J Neurosci. 2007;27:5394-404.

47. Tarkowski E, Blennow K, Wallin A, Tarkowski A. Intracerebral production of tumor necrosis factor-alpha, a local neuroprotective agent, in Alzheimer disease and vascular dementia. Clin Immunol. 1999;19:223-30.

48. Busche MA, Eichhoff $G$, Adelsberger $H$, Abramowski D, Wiederhold KH, Haass $C$, et al. Clusters of hyperactive neurons near amyloid plaques in a mouse model of Alzheimer's disease. Science. 2008;321:1686-9.

49. Birch AM, Katsouri L, Sastre M. Modulation of inflammation in transgenic models of alzheimer's disease. J Neuroinflammation. 2014;11:25.

50. Miller SL, Fenstermacher E, Bates J, Blacker D, Sperling RA, Dickerson BC. Hippocampal activation in adults with mild cognitive impairment predicts subsequent cognitive decline. J Neurol Neurosurg Psychiatry. 2008;79:630-5.

51. O'Brien JL, O'Keefe KM, LaViolette PS, DeLuca AN, Blacker D, Dickerson BC, et al. Longitudinal fMRI in elderly reveals loss of hippocampal activation with clinical decline. Neurology. 2010;74:1969-76. 